\title{
EFEITOS DA EDUCAÇÃO EM SAÚDE SOBRE ATITUDES DE IDOSOS E SUA CONTRIBUIÇÃO PARA A EDUCAÇÃO GERONTOLÓGICA
}

\author{
EFFECTS OF HEALTH EDUCATION ON THE ATTITUDES OF THE ELDERLY AND ITS \\ CONTRIBUTION TO GERONTOLOGICAL EDUCATION
}

\author{
Wanda Pereira Patrocinio ${ }^{1}$ \\ Beltrina da Purificação da Côrte Pereira ${ }^{2}$
}

Resumo O objetivo deste estudo é avaliar os efeitos de um programa de educação popular em saúde dirigido a idosos comunitários sobre suas atitudes em relação à velhice. O programa foi baseado na metodologia de Paulo Freire e na política de envelhecimento ativo da Organização Mundial da Saúde. Constou de 16 sessões semanais de 150 minutos, oferecidas a dois grupos de idosos $(\mathrm{n}=16)$ com 60 a 75 anos $(M=66,88 \pm 5,4)$. Foi realizado pré-teste, pós-teste e seguimento contendo medidas sociodemográficas, de saúde, de estilo de vida e de atitudes em relação à velhice. Análises de conteúdo mostraram diminuição estatisticamente significante na frequência de atitudes negativas, aumento das positivas e aumento da percepção de que a velhice comporta tanto ganhos quanto perdas. Os resultados sugerem que intervenções desse tipo podem favorecer a qualidade de vida de idosos, promovendo uma visão mais positiva da própria velhice. O programa desenvolvido também contribuiu para o cotidiano de profissionais que atuam na área de educação e saúde.

Palavras-chave velhice bem-sucedida; atitudes; programa de educação popular; educação em saúde.
Abstract The purpose of this study was to evaluate the effects of a popular health education program directed to community seniors with regard to their attitudes toward aging. The program was based on the Paulo Freire methodology and on World Health Organization's active aging policy. It consisted of 16 weekly 150-minute sessions offered to two groups of elderly $(n=16)$ aged 60 to 75 years $(M=66.88 \pm 5.4)$. Pre-testing, post-testing and follow-up were carried out to measure matters related sociodemographic, health, and lifestyle issues, as well as attitudes toward aging. Content analysis showed a statistically significant decrease in the frequency of negative attitudes, increased positive ones, and an improved perception that aging involves both gains as losses. The results suggest that such interventions can drive the quality of life of seniors by engendering a more positive view of old age itself. The program that was undertaken has also contributed to the daily lives of professionals working in the area of education and health.

Keywords successful old age; attitudes; popular education program; health education. 


\section{Introdução}

A educação de idosos no Brasil ocorre em vários contextos, entre eles nas universidades da terceira idade (Unatis), em programas socioeducacionais de instituições públicas e privadas, em salas de alfabetização para adultos e em programas desenvolvidos em unidades básicas de saúde, instituições de saúde e organizações não governamentais. Um dos aspectos essenciais para a eficácia do processo de ensino-aprendizagem na educação de pessoas de todas as idades é a formação do profissional que vai coordená-lo (Franco, Libâneo e Pimenta, 2007). A despeito do sensível aumento na oferta de programas educacionais para idosos no país nos últimos vinte anos, ainda não há um ponto de vista e nem um conjunto de práticas instituídas para a formação e o acompanhamento do trabalho educacional, assim como não se discutem sistematicamente fundamentos e práticas mais apropriadas ao processo de educação e aprendizagem para esse público. Tampouco existem claras políticas sociais e acadêmicas em relação ao tema.

A gerontologia educacional, segundo Cachioni (2008), é um campo interdisciplinar que se desenvolve no âmbito da educação de idosos e da formação de recursos humanos para lidar com a velhice, e na mudança das perspectivas das sociedades em relação aos idosos e ao envelhecimento.

A mesma autora publicou, em 2003, extensa pesquisa de levantamento sobre o perfil educacional e profissional de docentes de Unatis, suas crenças referentes à velhice e seus conhecimentos acerca da mesma, sem tratar das relações entre educação e aprendizagem de pessoas idosas. Essa é uma discussão mais do que necessária à formação de profissionais que atuam em Unatis - pedagogos, enfermeiros, psicólogos etc. - para que possam pensar sobre o que essa relação supõe para o discurso pedagógico e para a prática educativa e seus efeitos, especialmente no que diz respeito a uma construção pedagógica do ser, de como ele lida consigo, com o outro e com as perguntas de sua existência, de tal forma que o seu agir possa contribuir para o seu desenvolvimento pessoal e social.

Na pesquisa de Cachioni (2003), os participantes foram selecionados em instituições de Campinas (SP), Piracicaba (SP), Rio de Janeiro (RJ), Florianópolis (SC), Passo Fundo (RS) e Santa Maria (RS), escolhidas por representarem as principais modalidades de programas dessa natureza. Uma das conclusões da autora foi que programas educacionais necessitam de educadores que conheçam as características dos alunos idosos e que tenham competência técnica para desenvolver atividades docentes com eles, a fim de que esses programas possam melhor promover o bem-estar, a saúde e a qualidade de vida dos idosos.

Qualidade de vida é um conceito de múltiplas dimensões e determinações. Ele diz respeito à adaptação de indivíduos e grupos humanos em 
diferentes épocas e sociedades. Segundo Neri (2007b), o construto qualidade de vida está relacionado com aspectos objetivos e subjetivos, ligados às esferas econômica, social, cultural, psicológica e biológica. A qualidade de vida inclui ainda a avaliação subjetiva das condições de saúde e bem-estar e das condições de contexto, tendo em vista valores individuais e sociais. Tal constructo exerce influência no cotidiano de profissionais que atuam com idosos e que buscam auxiliar na melhora da qualidade de vida de seus atendidos.

O conceito de qualidade de vida relaciona-se com outra importante noção, a de envelhecimento saudável, processo e produto que envolve prevenção e controle de doenças, comportamentos de saúde (alimentação equilibrada, atividade física, sono, evitar fumo e álcool), atividade cognitiva e social, produtividade, participação social e objetivos e metas. Para a Organização Mundial da Saúde (2005), os três pilares do envelhecimento ativo são: saúde, participação social e proteção social. Mais recentemente, no Relatório Mundial da Saúde (2010), a OMS agregou um quarto elemento: a educação permanente. A promoção do envelhecimento saudável é de extrema relevância na presença do crescimento da população de idosos e do aumento da longevidade, porque auxilia a prevenir e a controlar a incidência de doenças crônico-degenerativas e da incapacidade.

$\mathrm{Na}$ investigação de fatores associados ao envelhecimento saudável, Moraes e Souza (2005) entrevistaram 400 idosos socialmente ativos na Região Metropolitana de Porto Alegre. Os resultados indicam que, para esses idosos, os fatores que influenciam o envelhecimento saudável são as relações familiares e de amizade, a saúde, e o bem-estar dela decorrente, a capacidade funcional e o suporte psicossocial. Boa saúde e independência funcional são elementos altamente valorizados pelos idosos, como se vê no estudo de Duay e Bryan (2006), que avaliaram as percepções de 18 idosos (11 mulheres e 7 homens) de 60 a 86 anos $(M=72,6)$ sobre envelhecimento bem-sucedido e sobre as estratégias que utilizavam para se adaptarem às mudanças. Na opinião dos idosos, o envelhecimento saudável envolve colaborar com os outros e ter boas relações sociais e familiares; saber lidar com as mudanças e limitações que o processo de envelhecimento propicia; e manter boa saúde física, mental e financeira. Dessa forma, conhecer a opinião dos idosos sobre o que é envelhecimento saudável é fundamental para que profissionais de diversas áreas compreendam o que o público idoso espera e deseja para envelhecer melhor.

Collins e Benedict (2006) avaliaram a eficácia de um programa educativo de promoção da saúde para idosos com duração de 16 semanas, relatando melhoras significativas na saúde e na qualidade de vida depois do programa. Sugerem que fatores relacionados à melhora da saúde e da qualidade de vida para idosos podem ser aprimorados pela educação, por contribuir 
para um maior conhecimento sobre a sua velhice e assim diminuir os fatores negativos percebidos nessa fase da vida, como a solidão e o estresse.

No Brasil, é importante enfatizar o papel desempenhado pelo Serviço Social do Comércio (Sesc) no atendimento a idosos nas áreas social, de saúde e da educação. Em 1977, tiveram início as Escolas Abertas da Terceira Idade (Serviço Social do Comércio, 2003), embrião das universidades abertas da terceira idade, que se desenvolveram a partir dos anos 1980 e 1990, com atuação de professores das áreas de educação, saúde e social. Cachioni (1998) e Ramos (2008) realizaram estudos nas Unatis que mostraram a importância da participação nessas instituições para o envelhecimento saudável e para a melhora na qualidade de vida dos idosos. Um estudo sobre duas Unatis da cidade de São Paulo (Patrocinio, 2011) considera que o idoso tem sua identidade e subjetividade construídas socialmente. A autora acredita que uma prática educacional que auxilie o idoso a se desenvolver seja aquela que lhe dê oportunidade de aprender sobre si mesmo, de conhecer a sua realidade e de fazer-se indivíduo ativo e capaz de agir sobre si próprio e o mundo.

No contexto da velhice, além da percepção dos idosos em relação ao significado do envelhecimento saudável, para que se chegue a essa fase da vida com saúde e bem-estar, é preciso considerar os hábitos de vida dos idosos, bem como seus comportamentos em relação à velhice. O comportamento de pessoas não idosas em relação aos idosos e dos idosos em relação à própria velhice depende da interação entre as diferentes crenças e entre os atributos cognitivos e afetivos das atitudes. Os comportamentos influenciam diretamente a mudança de atitudes e a forma como as pessoas lidam com os aprendizados em saúde. A forma como os idosos agirão em relação à própria saúde e a outros aspectos de suas vidas dependerá, em grande parte, das imagens de velhice e de suas atitudes em relação ao envelhecimento.

Atitudes são esquemas mentais que medeiam a relação entre o pensamento e o comportamento (Leal, Andrade e Queiroz, 2007). São essas crenças que intermediarão o valor que as pessoas dão para cuidar ou não de envelhecer com qualidade e de forma saudável. As atitudes podem ser consideradas predisposições socialmente aprendidas que se refletem nas avaliações de indivíduos e grupos sobre objetos sociais, e que envolvem processos afetivos, cognitivos e comportamentais. As atitudes em relação à velhice são aprendidas ao longo da vida por meio da convivência com idosos, pela experiência do próprio envelhecer e pelos meios simbólicos (Neri, 2007a e 2008).

Dos autores que fundamentam este estudo, observamos que Sáez Carreras (2003) ultrapassa a dimensão psicológica da educação, preocupando-se com a 'relação educativa'. O autor destaca que, na relação de aprendizagem da educação intergeracional, as pessoas idosas podem ser tanto sujeitos da educação quanto agentes educativos. Segundo ele, declaradamente um 'defensor apaixonado' das relações entre educação e pessoas idosas, vivemos momen- 
tos nos quais é preciso refletir e reelaborar uma educação de pessoas mais de acordo com a época; e os profissionais que atuam com idosos precisam estar preparados para isso, de modo a enfrentar essa nova realidade.

No Brasil, são ainda escassos os estudos de pensadores que, com base em uma relação educativa, repensam as atitudes dos idosos com a sua existência como ser humano e a sua vivência no ciclo vital. Por isso, é importante que sejam desenvolvidos estudos críticos sobre o tema. Essas iniciativas favorecerão a compreensão do fenômeno, bem como auxiliarão no fortalecimento daqueles que hoje estão na velhice, dentro de um projeto que dê sentido ao alargamento de sua vida.

Neri e Jorge (2006) deram alguns passos nesse sentido ao realizarem uma pesquisa com 227 estudantes de graduação em educação e em saúde sobre atitudes e conhecimentos em relação à velhice. Entre os estudantes de Pedagogia ( $\mathrm{n}=111), 82,88 \%$ não haviam sido expostos a disciplinas sobre velhice e 90,99\% disseram nunca ter lido livros sobre velhice. Os alunos da área de saúde que tinham tido disciplinas teóricas e práticas sobre a velhice $(75,98 \%)$ mostraram conhecer mais sobre os aspectos físicos, psicológicos e sociais do envelhecimento do que os que não tiveram. Para essas autoras, tais dados colocaram em evidência a importância dos estudos formais no estabelecimento de conhecimentos específicos sobre velhice.

Montanholi et al. (2006) estudaram atitudes de alunos de Enfermagem antes e depois de cursarem disciplinas sobre enfermagem gerontológica. Tais alunos inicialmente associavam velhice à exclusão e à inutilidade, e descreviam os idosos como indivíduos desrespeitados e desvalorizados; o mesmo ocorreu em outro estudo, com alunos que não cursaram o conteúdo de gerontologia (Novaes, 2001). Montanholi et al. (2006) ressaltaram que o contato com o idoso, nesse caso como agente educativo, desempenhou papel fundamental na reelaboração dos conceitos e das atitudes acerca do envelhecimento dos mais jovens.

Neri (2007a) relatou dados brasileiros sobre atitudes em relação à velhice, observando que $75 \%$ dos não idosos e $76 \%$ dos idosos acreditam existir predominância de atitudes negativas de diferentes gerações na sociedade em relação a essa etapa da vida. Segundo a autora, esses números replicam dados de estudos similares feitos em outros países (Bousfield e Hutchison, 2010; Hess, 2006; Kite et al., 2005), embora não haja uma única tendência nesse campo, como mostraram Hori e Cusack (2006) e Frumi e Celich (2006).

A predominância de atitudes negativas em relação à velhice é um fato que ocorre em todas as gerações. É necessária uma mudança dessas atitudes que contemple uma visão positiva do envelhecimento, a fim de que o envelhecer possa ser percebido pelas gerações como uma fase que comporta tanto ganhos quanto perdas - e, com isso, elas consigam vivenciá-lo de forma equilibrada e estruturada. 
Para a promoção da saúde em idosos, a perspectiva da educação popular de Paulo Freire (1975, 1979 e 1982) parece ser a mais apropriada, não apenas por utilizar conscientização e reflexão, mas também pelo fato de a organização dos conteúdos e das ações ter como ponto de partida os conhecimentos trazidos pelos aprendizes - e, ao mesmo tempo, agentes de processos de aprendizagem - e o contexto de cada grupo. Além disso, os aprendizes refletem criticamente acerca dos conteúdos e temas extraídos desta época e de sua vivência nela, e são estimulados pelos profissionais a se transformarem em agentes de novos conhecimentos na sua prática cotidiana. Os participantes se inserem na aprendizagem, fazendo-se parte do processo educativo e percebendo mais sentido em suas vivências, o que aumenta a chance de maior significado em sua vida.

Tendo em vista todo o debate apresentado sobre o tema, o problema desta pesquisa esteve ligado ao planejamento de programas educacionais dirigidos a idosos, realizados por profissionais das áreas de educação em saúde, e com enfoque no envelhecimento saudável e nas atitudes em relação à velhice. Este estudo preenche uma lacuna no campo da gerontologia, área que tem como objeto de estudo e prática a velhice e o envelhecimento. $\mathrm{O}$ reconhecimento da escassez de produção na área sobre atitudes desse segmento etário, num contexto de escassa percepção dos idosos como clientela merecedora de atenção, e a existência de estereótipos negativos segundo os quais os idosos são improdutivos e não flexíveis - e, assim, não merecedores de esforços educacionais - comprova isso.

Assim, este estudo consiste em um exercício que pretende dar a conhecer que a educação e o processo de aprendizagem não podem se limitar apenas ao campo da gerontologia. Nesse sentido, seus objetivos ${ }^{3}$ foram implantar e analisar os efeitos de um programa de educação popular em saúde dirigido a idosos comunitários sobre as atitudes dos mesmos em relação à própria existência nessa etapa de suas vidas. É um estudo fundamentado em Freire, para quem a educação "implica a consciência de mim no mundo, com ele e com os outros, que implica também a nossa capacidade de perceber o mundo, de compreendê-lo" (1995, p. 75-76). Almejou-se também auxiliar o idoso em seu processo de desenvolvimento pessoal e, consequentemente, na reflexão sobre melhoras para o seu envelhecimento saudável. Por fim, pretendeu-se contribuir no desenvolvimento de um programa que possa auxiliar outros profissionais em sua prática cotidiana de trabalho com idosos.

\section{Metodologia}

Foram realizadas intervenções de educação e aprendizagem em dois grupos de idosos residentes em dois bairros da cidade de Campinas (SP): Orosimbo 
Maia e Parque da Figueira, ambos localizados no Distrito de Saúde Sul. Entre os cinco distritos desse município, o Sul é o segundo com maior população de idosos (26,8\% do total), segundo dados do Censo 2000, atualizados em abril de 2010 (Campinas, 2007). Os idosos estavam referenciados ao Centro de Saúde Orosimbo Maia, que nucleia uma região com Índice de Vulnerabilidade Social (IVS) médio, e ao Parque da Figueira, que nucleia uma região com IVS baixo.

A escolha dos idosos seguiu duas estratégias. Uma delas foi a de contatar os idosos que haviam participado anteriormente de um estudo populacional sobre fragilidade, nos dois bairros selecionados. Esse contato foi feito por telefone e pessoalmente pelas mesmas agentes comunitárias de saúde (ACSs) que haviam colaborado no recrutamento dos participantes do estudo inicial. A segunda estratégia consistiu em divulgar o projeto por meio de cartazes e de convites pessoais feitos pela pesquisadora deste estudo em espaços de participação de idosos. Essa divulgação foi realizada em igrejas, parques, centros comunitários, centros de convivência e centros de saúde. O critério de seleção, comunicado aos participantes potenciais, era ter pelo menos 60 anos de idade e residir na comunidade em que a pesquisa seria desenvolvida.

Os idosos que se apresentaram como voluntários foram orientados a comparecer a uma reunião inicial, quando foram informados sobre os objetivos do estudo, a duração do programa e os resultados esperados. Compareceram a essa primeira reunião 26 idosos, sendo 20 do Orosimbo Maia e 6 do Parque da Figueira. Dentre os idosos que estiveram presentes à reunião, 16 aceitaram participar. A eles foram entregues a agenda do programa e as instruções de participação: comparecer para entrevista de realização do pré-teste na data e horário agendados e participar dos encontros semanais nos dias e horários acordados pelo grupo.

A idade média do grupo formado por 16 pessoas foi de 66,88 (desvio-padrão 5,4; idade mínima 60 anos e idade máxima 75 anos) e a maioria estava na faixa etária de 60 a 69 anos, sendo 15 idosas e 1 idoso. Dos integrantes, 5 eram do Parque da Figueira e 11 do Orosimbo Maia. Grande parte deles não trabalhava remuneradamente, mais da metade era aposentada e cinco recebiam pensão. Houve uma porcentagem maior $(80 \%)$ de pensionistas no grupo do Parque da Figueira ( $80 \%$ ) do que no do Orosimbo Maia; a escolaridade da maioria correspondeu ao primeiro ciclo do ensino fundamental; e a maior parte dos integrantes do grupo tinha renda mensal individual de até três salários mínimos. Havia mais casados no grupo Orosimbo Maia $(54,55 \%)$ e mais viúvas no Parque da Figueira (100\%). No tocante à experiência profissional, sete pessoas tinham sido faxineiras, empregadas domésticas e vendedoras; cinco eram donas de casa; uma era operadora de máquinas; um era forneiro industrial; uma era professora; e outra era auxiliar de enfermagem. 
Foram realizadas medidas de pré-teste, pós-teste e seguimento com apoio em instrumentos de natureza sociodemográfica, de avaliação de atitudes e de imagem sobre a velhice. Aspectos selecionados das sessões de intervenção educacional foram registrados por uma auxiliar de pesquisa, treinada para a tarefa, que anotou a participação verbal dos idosos em planilhas específicas. A auxiliar de pesquisa também fez registros cursivos das intervenções dos idosos relacionadas com comportamentos e atitudes negativas ou positivas vividas no dia a dia.

As medidas de pré-teste, pós-teste e seguimento foram aplicadas individualmente, em situação de entrevista, pela pesquisadora ou pela auxiliar de pesquisa. Em data pré-agendada com os idosos que participaram da reunião de apresentação do projeto, realizou-se a assinatura do termo de consentimento livre e esclarecido e, em seguida, foi aplicado o pré-teste; o pós-teste foi realizado em data combinada na última sessão e o seguimento, seis meses depois do término do programa, em data e local combinados com os participantes. Os idosos responderam oralmente, e as informações foram registradas pela pesquisadora ou pela auxiliar de pesquisa no protocolo de coleta de dados. O projeto foi aprovado pelo Comitê de Ética em Pesquisa da Faculdade de Ciências Médicas da Universidade Estadual de Campinas (FCM/Unicamp).

A intervenção consistiu na aplicação de um programa de educação popular em saúde visando ao envelhecimento saudável, fundamentado pelo modelo de educação dialógica e popular de Paulo Freire e pela política de envelhecimento ativo proposta pela Organização Mundial da Saúde (OMS) (2005), fundada nos pilares saúde, participação social, proteção e treinamento contínuo. A proposta de educação desenvolvida por Paulo Freire (1975, 1979 e 1982) visa desenvolver nas pessoas não apenas o reconhecimento de si mesmas como sujeitos, mas também uma visão crítica sobre as estruturas sociais e o engajamento ativo em uma prática emancipadora. Ela implica processos contínuos e permanentes de formação, num contexto de confiança mútua. As atividades devem favorecer a autonomia, a participação, a colaboração, a exploração de pontos de vista alternativos, a problematização e a reflexão crítica. Os conceitos básicos subjacentes a essa proposta de educação são a conscientização, que deve acompanhar o processo educativo; as relações dialógicas entre educador e educando; e o caráter transformador da educação, que deve preocupar-se com o bem-estar dos indivíduos.

O programa foi realizado com um encontro semanal de cerca de 150 minutos, durante quatro meses, para cada um dos grupos, totalizando 16 sessões no grupo do bairro Orosimbo Maia e 15 no do Parque da Figueira. A cada encontro, a auxiliar de pesquisa realizava registros de acompanhamento de cada participante (avaliação processual). 
Logo depois do pré-teste, foram apresentados para os participantes os possíveis conteúdos a serem trabalhados na intervenção e foi pedido a eles que apontassem os que lhes pareciam prioritários. Os temas escolhidos pelos grupos foram memória, distúrbios do sono, atividade física, alimentação saudável, saúde bucal, emoções e sentimentos na velhice, uso de medicamentos, instruções sobre saúde, imagem positiva do envelhecimento, maus-tratos a idosos e atividades terapêuticas (lian gong, tai chi chuan, yoga, massagem e argila terapêutica). Os programas foram organizados com base nesses temas, que ultrapassam as fronteiras disciplinarias.

No início de cada sessão, a professora apresentava o tema para os participantes e provocava uma discussão ou reflexão, ora em grupo, ora individual, sobre o assunto, a partir das quais a aula de caráter participativo se desenvolvia. Foram adotadas várias formas de desenvolvimento dos encontros educativos. A equipe de trabalho foi constituída por pesquisadora (que também atuou como professora nos encontros) e auxiliar de pesquisa; em alguns encontros, contou-se com a figura de uma agente comunitária de saúde. Profissionais das áreas de fonoaudiologia, odontologia, educação física, medicina e psicologia auxiliaram a pesquisadora com conteúdos para o programa, a fim de que ele fosse realizado de forma multidisciplinar. Esses profissionais se reuniram previamente com a pesquisadora para orientação, dicas de conteúdo e modo de abordagem nos seguintes temas: memória, saúde bucal, atividade física, tai chi chuan, uso de medicamentos e emoções e sentimentos na velhice.

Para os dados qualitativos, foi realizada análise de conteúdo (Bardin, 2004) dos registros relativos aos autorrelatos, coletados mediante questões abertas, e aos dados produzidos pela pesquisadora no decorrer da aplicação do programa. A fim de complementar os dados, foi realizada análise estatística sobre as imagens da velhice, utilizando o teste de Friedman.

\section{Resultados}

Por meio da análise de conteúdo das respostas estruturadas pelos idosos no pré-teste, pós-teste e seguimento, os resultados sobre as imagens de velhice foram divididos em dois grupos, respostas negativas e positivas, e de acordo com as categorias de análise utilizadas no planejamento do programa: a) saúde, com os temas doenças, problemas de saúde, hábitos de vida, atividade física, dieta e práticas de autocuidado; b) sociabilidade, com os temas: relação com amigos e familiares, envolvimento na igreja ou na comunidade, passeios, lazer e trabalho; c) aspectos psicológicos, com os temas: felicidade, ânimo, tristeza, solidão, satisfação e memória.

Cada participante pôde citar até três aspectos dentro da opção escolhida (ganhos e vantagens; perdas e limitações; tanto ganhos quanto perdas). 
Resultados do pré-teste para imagens negativas: 15 citações na categoria saúde, 6 referências à sociabilidade e 13 referentes a aspectos psicológicos, totalizando 35 opiniões negativas sobre a velhice. Resultados do pré-teste para imagens positivas: uma citação na categoria saúde, 10 referências à sociabilidade, 9 em aspectos psicológicos e 8 menções a ganhos de conhecimento, totalizando 28 opiniões positivas sobre a velhice.

Resultados do pós-teste para imagens negativas: 13 citações na categoria saúde, 3 referências à sociabilidade e 7 a aspectos psicológicos, totalizando 23 opiniões. Resultados do pós-teste para imagens positivas: 3 citações na categoria saúde, 15 referências à sociabilidade, 9 menções a aspectos psicológicos e 8 referências a ganhos de conhecimento, totalizando 35 opiniões.

Resultados do seguimento para imagens negativas: 17 citações na categoria saúde, 3 referências à sociabilidade e 7 a aspectos psicológicos, totalizando 27 opiniões. Resultados do seguimento para imagens positivas: 7 citações na categoria saúde, 14 referências à sociabilidade, 12 a aspectos psicológicos e 2 menções a ganhos de conhecimento, totalizando 35 opiniões.

As respostas dos participantes em relação às imagens negativas e positivas nos três tempos de medida são apresentadas no quadro 1, que traz as informações agrupadas por similaridade.

\title{
Quadro 1
}

Respostas negativas e positivas para a categoria imagens da velhice: Programa de Educação Popular em Saúde para um Envelhecimento Saudável (Campinas, 2009)

\begin{tabular}{ll}
\hline Negativas & Positivas \\
\hline
\end{tabular}

\begin{tabular}{|c|c|}
\hline & Doenças e perda de saúde \\
\hline & Dificuldade para se alimentar \\
\hline & Cansaço físico/perda de energia \\
\hline & Limitações físicas/fragilidade \\
\hline & Desânimo/desesperança/perda de vontade \\
\hline & Solidão \\
\hline Pré-teste & Decepções \\
\hline & Problemas de memória \\
\hline & Medo em relação ao futuro \\
\hline & Descaso das pessoas e da família \\
\hline & Perda de remuneração \\
\hline & Perda de entes queridos \\
\hline
\end{tabular}

\author{
Experiência, maturidade e aprendizagem \\ Ter acesso a atividades e cursos \\ Família \\ Benefícios: ter dois salários (trabalho e \\ aposentadoria) e atendimento preferencial \\ Ter saúde e disposição \\ Vida boa, conquistas que teve, tranquilidade \\ e descompromisso \\ Ocupação da mente \\ Tempo maior para coisas diferentes \\ Confiança das pessoas nele \\ Paciência e capacidade de entender melhor \\ as pessoas
}

continua > 


\section{Continuação - Quadro 1}

Respostas negativas e positivas para a categoria imagens da velhice: Programa de Educação Popular em Saúde para um Envelhecimento Saudável (Campinas, 2009)

\begin{tabular}{|c|c|c|}
\hline & Negativas & Positivas \\
\hline \multirow{14}{*}{ Pré-teste } & Perda de disposição/saúde & Evolução, aprendizagem e experiência \\
\hline & Cansaço/dores no corpo/limitações físicas & Participação em reuniões, mais \\
\hline & Quedas/fraturas & oportunidades, amizades, passeios e \\
\hline & Problemas de visão & programas de saúde \\
\hline & Solidão & Família e relações harmoniosas \\
\hline & Desânimo & Benefícios: atendimento preferencial e \\
\hline & Esquecimento/problemas de memória & gratuidade no transporte coletivo \\
\hline & Dificuldade em aceitar o ritmo mais lento & Ganhar mais saúde com os exercícios; sentir- \\
\hline & Doenças na família/perdas & -se fisicamente melhor e com mais disposição \\
\hline & Falta de independência na moradia & Ter mais autonomia e independência, \\
\hline & & receber pensão e não pagar aluguel \\
\hline & & Entender a velhice mais positivamente \\
\hline & & Sair mais e ter tempo para aproveitar a vida \\
\hline & & Maior aceitação e compreensão das pessoas \\
\hline \multirow{15}{*}{ Seguimento } & Dores/menor força física & Experiência e poder passar conhecimento \\
\hline & Cansar-se com maior facilidade/o corpo já não & Fazer mais coisas que não fazia antes; poder \\
\hline & aguenta mais & fazer artesanato, ter mais amizades \\
\hline & Agravamento de doenças/perda de saúde & Família e participação na comunidade \\
\hline & Perda da beleza & Benefícios: aposentadoria e poder ficar em \\
\hline & Alimentação restrita & casa, sem trabalhar \\
\hline & Comodismo/perda de otimismo & Ter saúde para fazer as coisas sem precisar \\
\hline & Esquecimento/problemas de memória & de ajuda, poder caminhar e ter disposição; \\
\hline & Solidão & Poder viver e comer bem, estar bem de vida \\
\hline & Não aceitação da velhice & Ter pensamento e ações positivas \\
\hline & Falta de ajuda de familiares & Ter mais consciência do que é certo e do que \\
\hline & Não poder mais andar ou sair sozinho & é errado, autoestima e pensar melhor \\
\hline & & Ter mais tempo para sair e passear \\
\hline & & Respeito; capacidade maior de compreensão \\
\hline & & das pessoas e mais paciência \\
\hline
\end{tabular}

Fonte: as autoras.

Do pré-teste ao pós-teste houve uma diminuição no número de opiniões com imagens negativas da velhice; essa diminuição não se manteve no seguimento. Foram 35 emissões negativas no pré-teste, 23 no pós-teste e 27 no seguimento. Em relação às imagens positivas, houve, do pré-teste ao pós-teste, um aumento no número de opiniões que se manteve no seguimento, passando de 28 emissões positivas no pré-teste para 35 no pós-teste e no seguimento. A análise estatística mostrou ocorrência de diferença significativa (teste de Friedman $\mathrm{p}=0,042)$ entre as imagens no pós-teste e no seguimento na categoria ambos (tanto ganhos quanto perdas), como mostra o gráfico 1 . 
Gráfico 1

Imagem da velhice: Programa de Educação Popular em Saúde para um Envelhecimento Saudável (Campinas, 2009)

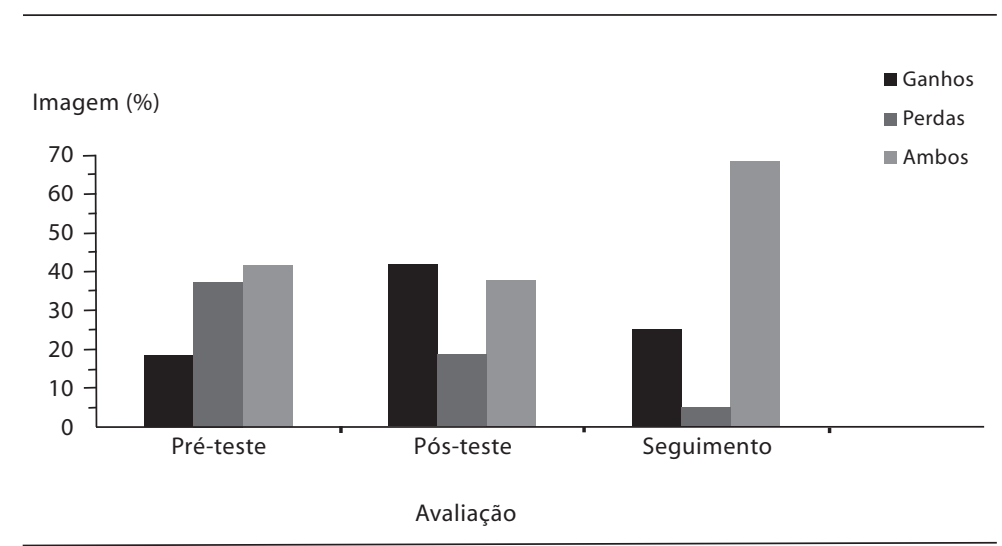

Fonte: Patrocinio (2011).

Quando entrevistados seis meses após o encerramento do programa, a maioria dos participantes $(81 \%)$ relatou que continuava a colocar em prática algum aspecto aprendido no programa educacional. As repostas foram majoritariamente voltadas para os aspectos da categoria saúde, com 15 citações sobre cuidado com a respiração, com a alimentação (mudança no modo de se alimentar, comer alimentos que não comia antes), com as práticas de prevenção de doenças, ginásticas aprendidas, observação da postura ao caminhar, sentar e deitar e cuidar mais de si próprio. Houve nove citações variadas, como pensar mais nos problemas e buscar soluções, estudar as apostilas e textos, prestar mais atenção nos eventos e realizar os exercícios de memória aprendidos.

\section{Discussão}

Este estudo buscou implantar e analisar o impacto de um programa de educação popular em saúde aplicado a idosos comunitários sobre atitudes em relação à velhice e ao envelhecimento saudável - um programa de educação focado, portanto, na velhice e no envelhecimento. De acordo com Assis et al. (2009), há escassez de trabalhos avaliativos sobre as atividades realizadas com grupos de idosos. Além disso, vários estudos são relatos de experiências com aspectos avaliativos de base qualitativa e não propriamente pesquisas com fins de avaliação (Assis, Hartz e Valla, 2004).

O trabalho realizado procurou contribuir para a obtenção de dados sobre atitudes dos idosos em relação ao próprio processo de envelhecimento, 
uma vez que ainda são escassos no Brasil os trabalhos que avaliam as opiniões dos idosos. O que se encontra são, em sua maioria, pesquisas voltadas para as atitudes de não idosos em relação à velhice. Secundariamente, a pesquisa também beneficiou os profissionais que acompanharam o trabalho, como mostra o relato da profissional que auxiliou durante a pesquisa:

Decidi participar da pesquisa, pois tenho pais idosos e me interessei em saber mais sobre esse tema, mas confesso que também decidi participar desse grupo para interagir com outras pessoas e me sentir viva. Esse grupo realmente vale a pena, preenche (I., 45 anos).

As atitudes foram estudadas com base na imagem de velhice dos participantes. A percepção de velhice está predominantemente associada a doenças e debilidades físicas, como apresentado nos estudos de Lopes (2007), Patrocinio e Gatti (2006) e Patrocinio e Gohn (2005). Na pesquisa realizada com os idosos do presente estudo, verificou-se que em mais de $80 \%$ das respostas dos participantes havia, no início do programa, a menção à presença de perdas na velhice. Como exemplos, citamos a opinião de duas participantes:

A sociedade considera que o idoso não presta, não serve mais para nada (Dona A., 64 anos).

Em todo médico que vou, falam que é tudo da idade (Dona Es., 75 anos).

Apesar de as pessoas saberem o que faz mal à saúde e quais tarefas são necessárias para a promoção da saúde, é difícil alterar comportamentos e atitudes pessoais nessa questão. Também é difícil mudar crenças e atitudes das pessoas sobre a prevenção, sem antes mudar as concepções causais adquiridas por elas ao longo da vida (Reis e Fradique, 2003). A implantação de um programa de educação sobre conteúdos de saúde, psicológicos, interações sociais e imagens da velhice pode contribuir para a mudança da imagem negativa, possibilitando alterações nas atitudes em relação à própria velhice dos participantes e para a mudança de comportamentos. Ou seja, acredita-se na educação como veículo de mudança de atitudes em relação à velhice (Todaro, 2009), como se pode notar no relato da profissional que acompanhou a pesquisa em uma das últimas aulas do programa:

Hoje especialmente notei que as senhoras estavam mais vivazes, bonitas, cabelos cortados. Acredito que a autoestima do grupo está em alta (I., 45 anos).

Os resultados mostraram que houve mudança em relação à imagem de velhice, pois diminuíram as opiniões negativas e aumentaram as positivas. 
Na pesquisa SESC/Fundação Perseu Abramo, a imagem da velhice apontada estava predominantemente ligada a atributos negativos em todas as faixas etárias pesquisadas (Lopes, 2007).

No estudo de Pereira et al. (2009), a insatisfação com a própria imagem corporal está relacionada, entre outros fatores, às modificações físicas e psicológicas decorrentes do envelhecimento. Caetano et al. (2009) perceberam que um programa de atividade física para mulheres incontinentes causou mais impacto na qualidade de vida do que na autoimagem delas. No estudo de Leal, Andrade e Queiroz (2007), as autoras acreditam que a maioria dos idosos apresentava uma atitude negativa diante da velhice, pois quando falavam de envelhecimento, deslocavam-se do papel de sujeito, passando para o de espectador da situação.

Esse deslocamento decorre possivelmente do preconceito que os indivíduos têm em relação à velhice, resultado da sua experiência tanto pessoal quanto social, e também da sua relação com os profissionais no âmbito da saúde. Para as autoras, a visão da sociedade e de cada indivíduo influencia como e quando os idosos se assumirão como tal, pois as atitudes da sociedade com relação ao idoso interferem na sua autoimagem, determinando as lentes pelas quais a velhice é vista. Tribess, Virtuoso Junior e Petroski (2010) acreditam que o entendimento dos aspectos que influenciam a satisfação da imagem corporal no idoso é determinante na elaboração de intervenções de profissionais preocupados com o bem-estar desse público.

Alguns participantes, no início do programa, apresentaram uma imagem dos idosos cansados fisicamente; já no final do trabalho, imaginaram um futuro mais saudável:

Daqui a dez anos eu vou estar dançando. Eu sou ótima em desenho. Eu vou estar desenhando (Dona S., 61 anos).

Esse resultado pode ter sido influenciado pela participação no programa, pelos aprendizados que tiveram e por perceberem que é possível envelhecer com saúde. Talvez esse dado mostre uma mudança na imagem do idoso. Assim, a imagem anterior ao programa de que o idoso envelheceria sozinho muda para uma imagem de idosos acompanhados de outros em sua velhice, como mostra a fala de uma das participantes:

Eu quero que a minha velhice termine assim, no meio de muita gente. Não quero ficar só (Dona T., 74 anos).

Hori e Cusack (2006) relataram relação positiva entre atitudes em relação à velhice e a participação em centros de educação. Os idosos participantes do programa de educação popular em saúde relataram no pós-teste que 
um dos maiores ganhos de sua participação foi a ampliação das relações sociais e da interação com outras pessoas. O mesmo se deu no estudo de Rizzolli e Surdi (2010), no qual um dos resultados esteve relacionado ao aumento das amizades, sendo esse um fator que influencia a continuidade dos idosos nos programas e as mudanças positivas que ocorrem na vida dessas pessoas.

Estudioso de Paulo Freire, Zitkoski (2010) nos diz que o ser humano se constitui dialeticamente e, por isso mesmo, dialogicamente com o mundo. Isso implica dizer que o programa de educação em saúde foi percebido pelos próprios participantes como uma estratégia que possibilitou promover uma relação dialógica: conviver, ser com os outros e humanizar-se em comunhão. Segundo Zitkoski, "o diálogo que alimenta a comunicação é a alavanca do verdadeiro processo educativo do ser humano" (2010, p. 23). Portanto, o programa, antes centrado na velhice e no envelhecimento, passou a focar o ser no mundo, independentemente da idade.

Houve um resultado muito interessante de uma participante que, ao se ter como base as considerações de Goldfarb (1998) e Neri (2007a), pode ser generalizado para a questão da imagem na velhice e, especificamente, para a velhice em termos de gênero. Essa idosa demonstrou no primeiro trabalho sobre imagem uma autoimagem negativa, relatando que não conseguia se olhar no espelho nem aceitar a própria velhice, que era triste e que se sentia muito vazia. Na segunda imagem, ao final do programa, não escreveu nada, mas não apresentou tanta revolta e falta de aceitação como no primeiro momento.

Segundo Goldfarb (1998), no campo do reconhecimento da imagem que os indivíduos possuem sobre o próprio corpo, quando se adentra na década de 1950 e dos 60 anos de vida, ocorre uma estranheza ante a própria imagem, chamada pela autora de espelho negativo. Essa estranheza aparece antes de a velhice se instalar: é um fenômeno que anuncia a velhice em termos de estética, ou seja, a primeira percepção que se tem em relação ao próprio corpo aparece em termos corporais, em que não se tem mais aquele corpo 'perfeito' e bem definido da juventude. E isso pode acarretar não aceitação e dificuldades em lidar com essa nova fase da vida. Além disso, as mulheres costumam apresentar uma autoimagem e imagens da velhice mais negativas, porque a perda da beleza e do vigor físico oneram mais as mulheres do que os homens (Neri, 2007a).

Esse mesmo caso, da idosa que apresentou autoimagem negativa, na perspectiva freiriana, nos diz que "a educação problematizadora (...) identifica-se com o próprio da consciência que é sempre ser consciência de, não apenas quando se intenciona a objetos, mas também quando se volta sobre si mesma" (Freire, 1993, p. 67), o que, segundo Zitkoski (2010), nos leva a repensar as tramas e potencialidades do existir humano no mundo sociocultural da atualidade. 
A atitude dos idosos em relação ao próprio processo de envelhecimento pode ser modificada com a participação em universidades abertas à terceira idade, como mostraram os estudos de Cachioni (1998) e Ramos (2008). Também pode ir mais além desse tipo de participação, com a mudança de atitude em relação à sua própria existência por meio da integração em programas educacionais, sociocomunitários ou de saúde, envolvendo a relação com outros e a ressignificação de seus projetos de vida. Quando tais atividades são realizadas de forma participativa e dialógica, os envolvidos no processo consideram o conhecimento de vida de cada participante e valorizam as suas histórias de vida, passando a ser agentes educativos de si mesmos. A valorização e o respeito por parte dos profissionais que acompanham os idosos fazem que eles percebam sentido e significado no seu processo de vida e, consequentemente, no seu envelhecer, além de contribuírem para a experiência de trabalho dos profissionais, como mostra o relato da auxiliar de pesquisa:

A pesquisa de campo foi fundamental, pois possibilitou a interação entre os idosos e a equipe, e entre o grupo como um todo. Para mim, foi uma experiência muito enriquecedora conviver com o grupo, pois muitas vezes, dependendo do tema e período de nosso trabalho, não conseguimos estar próximos das pessoas que fazem parte de nossas atividades (I., 46 anos).

Na pesquisa de Frumi e Celich (2006), os idosos pesquisados não revelavam atitudes negativas em relação à velhice, mas sim a sua aceitação e a percepção de que o envelhecimento é um processo natural do ciclo vital do ser humano e de qualquer outro ser vivo, de que o idoso tem melhor consciência do que está vivenciando e sua adaptação é mais bem realizada quando ele está mais saudável e otimista. Na pesquisa com os idosos comunitários, percebeu-se que a mudança na percepção da velhice se deu na relação com os outros, com a significativa diminuição das crenças na velhice associada a aspectos negativos, e com a possibilidade de enxergar essa fase da vida de forma mais balanceada, pois, ao se colocar na balança todo o vivido, foi possível dar peso também para os ganhos que a velhice proporciona, ocasionando uma consciência de atitudes mais positivas sobre o viver.

Em relação às categorias de conteúdo surgidas na relação educativa, foi possível notar que os aspectos de saúde, psicológicos e sociais estiveram presentes nas três medidas de seguimento e nos três eixos de respostas (ganhos, perdas e tanto um quanto o outro). A diferença marcante esteve presente no tipo de resposta que os idosos deram nas respectivas categorias. Por exemplo, na categoria saúde, para uns ter dores e doenças era visto como uma característica negativa da velhice; para outros, ter dor, mas ainda assim ter saúde e disposição, era visto como algo positivo na velhice. 
De modo geral, o programa proporcionou processos de aprendizagens observados na análise de conteúdo das narrativas dos idosos, principalmente no tocante a aspectos psicossociais, como paciência, ânimo, motivação para a mudança, senso de competência e melhora na comunicação com outras pessoas. Na análise de conteúdo, foram observados resultados significativos no que diz respeito à mudança de atitudes em relação a si, ao outro e à velhice.

\section{Considerações finais}

Partir de um programa educacional realizado de forma multidisciplinar, tendo inicialmente como objeto de estudo e prática a velhice e o envelhecimento, e chegar a um processo educativo que revelou as potencialidades do existir humano na atualidade permite-nos considerar que o programa promoveu relações educativas e dialógicas, as quais, por sua vez, transformaram o próprio objeto e a prática deste estudo, ao passarmos a ver a pessoa em relação com o mundo e não apenas com o seu envelhecimento.

Acredita-se na importância da formação do profissional que queira desenvolver atividades relativas aos idosos, no sentido de ser necessário que tenha compreensão não apenas didática como também da complexidade que envolve o ser humano nas suas diferentes etapas de vida, especialmente quando se experiencia pela primeira vez na história da humanidade o alargamento dos anos de vida.

A implantação de um programa de educação popular em saúde visando melhorar a existência das pessoas exige um profissional para o qual a velhice seja uma idade diferente, e não uma idade de perdas. Este estudo, ao pretender contribuir com a mudança de atitudes em relação à velhice de idosos residentes na comunidade, resultou em uma investigação que relaciona as pessoas em seu processo educativo, buscando, a partir daí, extrair conhecimentos que possam ajudar-nos a superar a negatividade da percepção funcionalista da velhice, mediante intervenções educativas resultantes das mesmas.

Os resultados desta pesquisa sugerem que intervenções desse tipo podem favorecer a 'consciência de ser no mundo, com ele e com os outros' do idoso, e, assim, contribuir para uma visão mais positiva da sua própria velhice, como aconteceu com os participantes desta pesquisa, os quais, como agentes educativos de seu processo, apresentaram mudanças atitudinais nos hábitos de vida, na saúde e em suas perspectivas, mediadoras de mudanças de paradigmas. 


\section{Colaboradores}

As autoras trabalharam juntas em todas as etapas do manuscrito.

\section{Notas}

1 Coordenadora do curso de Especialização em Gerontogeriatria do Centro Universitário de Lins (Unilins), Lins, São Paulo, Brasil. Doutora em Educação pela Universidade Estadual de Campinas (Unicamp). <wanda@gerovida.com.br>

Correspondência: Rua Marcello de Almeida, 112, Condomínio Zermatt, Swiss Park, Campinas, São Paulo, Brasil, CEP 13049-437.

2 Professora assistente do Programa de Estudos Pós-graduados em Gerontologia da Pontifícia Universidade Católica de São Paulo (PUC-SP), São Paulo, São Paulo, Brasil. Pós-doutora em Ciências da Comunicação pela Universidade de São Paulo (USP). $<$ beltrina@pucsp.br>

3 Texto baseado nas discussões realizadas durante a arguição da defesa de tese de doutorado da primeira autora.

\section{Referências}

ASSIS, Mônica et al. Avaliação do projeto de promoção da saúde do Núcleo de Atenção ao Idoso: um estudo exploratório. Interface: comunicação, saúde, educação, Botucatu, v. 13, n. 29, p. 367-386, abr./ jun. 2009.

; HARTZ, Zulmira M. A.; VALLA, Victor V. Programas de promoção da saúde do idoso: uma revisão da literatura científica no período de 1990 a 2002. Ciência \& Saúde Coletiva, Rio de Janeiro, v. 9, n. 3, p. 557-581, 2004.

BARDIN, Laurence. Análise de conteúdo. 4. ed. Lisboa: Edições 70, 2004.
BOUSFIELD, Catherine; HUTCHISON, Paul. Contact, anxiety and young people's attitudes and behavioral intentions towards the elderly. Philadelphia, Educational Gerontology, v. 36, n. 6, p. 451-466, 2010.

CACHIONI, Meire. Envelhecimento bemsucedido e participação numa universidade para a terceira idade: a experiência dos alunos da Universidade São Francisco. 1998. Dissertação (Mestrado em Educação) - Faculdade de Educação, Universidade Estadual de Campinas, Campinas, 1998. 
Gerontologia educacional e educação gerontológica. In: NERI, A. L. (Org.). Palauras-chave em gerontologia. Campinas: Alínea, 2005. p. 92-94.

. Quem educa os idosos?: um estudo sobre professores de universidades da terceira idade. Campinas: Alínea, 2003.

CAETANO, Aletha S. et al. Influência da atividade física na qualidade de vida e autoimagem de mulheres incontinentes. Revista Brasileira de Medicina do Esporte, São Paulo, v. 15, n. 2, p. 93-97, mar./abr. 2009.

SÃO PAULO (Estado). Prefeitura Municipal. Secretaria de Saúde. 2010. Disponível em: http://tabnet.saude.campinas.sp.gov.br.

Acesso em: 5 abr. 2010.

COLLINS, Claudia C.; BENEDICT, Jamie. Evaluation of a community-based health promotion program for the elderly: lessons from seniors. American Journal of Health Promotion, v. 21, n. 1, p. 45-48, 2006.

DUAY, Deborah B.; BRYAN, Valerie C. Senior adults' perceptions of successful aging. Educational Gerontology, Philadelphia, v. 32, n. 6, p. 423-445, 2006.

FRANCO, Maria A. S.; LIBÂNEO, Jose C.; PIMENTA, Selma G. Elementos para a formulação de diretrizes curriculares para cursos de pedagogia. Cadernos de Pesquisa, São Paulo, v. 37, n. 130, p. 63-97, jan./abr. 2007.

FREIRE, Paulo. À sombra desta mangueira. São Paulo: Olho d'Água, 1995.

Educação e mudança. 24. ed. Rio de Janeiro: Paz e Terra, 1979.

. Extensão ou comunicação?. 2. ed. Rio de Janeiro: Paz e Terra, 1975.

. Pedagogia do oprimido. 11. ed. Rio de Janeiro: Paz e Terra, 1982.

FRUMI, Cailene; CELICH, Kátia L. S. O olhar do idoso frente ao envelhecimento e à morte. Revista Brasileira de Ciências do En- velhecimento Humano, Passo Fundo, p. 92100, jul./dez. 2006.

GOLDFARB, Della C. Corpo, tempo e envelhecimento. São Paulo: Editora do Psicólogo, 1998.

HESS, Thomas. Attitudes toward aging and their effects on behavior. In: BIRREN, James E.; SCHAIE, K. (Org.). Handbook of the Psychology of Aging. San Diego: Academic Press, 2006. p. 379-406.

HORI, Shigeo; CUSACK, Sandra. Third-age education in Canada and Japan: attitudes toward aging and participation in learning. Educational Gerontology, Philadelphia, v. 32, n. 6, p. 463-481, 2006.

KITE, Mary E. et al. Attitudes toward younger and older adults: an update metaanalytic review. Journal of Social Issues, Washington(DC), v. 61, n. 2, p. 241-266, 2005.

LEAL, Viviane C. T.; ANDRADE, Évora F. A.; QUEIROZ, Jaqueline T. A influência das experiências sociais na atitude dos idosos em relação ao envelhecimento. In: ENCONTRO NACIONAL DA ASSOCIAÇÃO BRASILEIRA DE PSICOLOGIA SOCIAL, 14., 2007, Rio de Janeiro. Anais... Rio de Janeiro, 2007. Disponível em: <http://www.abra pso.org.br/siteprincipal/anexos/AnaisXIVEN A/conteudo/pdf/trab_completo_272.pdf.>. Acesso em: 17 dez. 2012.

LOPES, Ruth G. C. Imagem e autoimagem: da homogeneidade da velhice para a heterogeneidade das vivências. In: NERI, Anita L. (org.). Idosos no Brasil: vivências, desafios e expectativas na terceira idade. São Paulo: Perseu Abramo-Edições Sesc, 2007. p. 141-152.

MONTANHOLI, Liciane L. et al. Ensino sobre idoso e gerontologia: visão do discente de enfermagem no estado de Minas Gerais. Texto \& contexto: enfermagem, Florianópolis, v. 15, n. 4, p. 663-671, out./dez. 2006.

MORAES, João F. D.; SOUZA, Valdemarina B. A. Fatores associados ao envelhecimento bem-sucedido de idosos socialmente ativos 
da Região Metropolitana de Porto Alegre. Revista Brasileira de Psiquiatria, São Paulo, v. 27, n. 4, p. 302-308, 2005.

NERI, Anita L. (Org.). Idosos no Brasil: vivências, desafios e expectativas na terceira idade. São Paulo: Perseu Abramo-Edições Sesc, 2007a.

(Org.). Palauras-chave em gerontologia. 3. ed. Campinas: Alínea, 2008.

Qualidade de vida na velhice: enfoque multidisciplinar. Campinas: Alínea, 2007b.

JORGE, Mariana D. Atitudes e conhecimentos em relação à velhice em estudantes de graduação em educação e em saúde: subsídios ao planejamento curricular. Estudos de Psicologia, Campinas, v. 23, n. 2, p. 127-137, abr./jun. 2006.

NOVAES, Márcia R. V. As representações sociais dos alunos de graduação em enfermagem sobre "ser velho" e "cuidar de velhos". 2001. Dissertação (Mestrado em Saúde Pública) - Faculdade de Saúde Pública, Universidade de São Paulo, São Paulo, 2001.

ORGANIZAÇÃO MUNDIAL DA SAÚDE (OMS). Envelhecimento ativo: uma política de saúde. Brasília: Organização Pan-Americana da Saúde, 2005.

PATROCINIO, Wanda P. Descrição e análise dos efeitos de um programa de educação popular em saúde dirigido a idosos comunitários. 2011. Tese (Doutorado em Educação) - Faculdade de Educação, Universidade Estadual de Campinas, Campinas, 2011.

; GATTI, Patrícia. Envelhecimento, trabalho e educação: um estudo sobre cooperativas populares. In: GUSMÃO, Neusa M. M.; VON SIMSON, Olga R. M. (Org.). Velhice e diferenças na vida contemporânea. Campinas: Alínea, 2006. p. 75-105.

; GOHN, Maria G. M. Experiências e representações sociais de trabalhadores e trabalhadoras sobre seu próprio processo de envelhecimento em cooperativas populares. Revista Kairós: Gerontologia, São Paulo, v. 8, n. 2, p. 119-138, 2005.

PEREIRA, Érico F. et al. Relação entre diferentes indicadores antropométricos e a percepção da imagem corporal em idosas ativas. Revista de Psiquiatria Clinica, São Paulo, v. 36, n. 2, p. 54-59, 2009.

RAMOS, Vania. Velhas e velhos conquistam espaços nas universidades de São Paulo: política, sociabilidade e educação. 2008. Tese (Doutorado em Ciências Sociais) - Faculdade de Ciências Sociais, Pontifícia Universidade Católica de São Paulo, São Paulo, 2008.

REIS, Joaquim C.; FRADIQUE, Fernando S. Significações sobre causas e prevenção das doenças em jovens adultos, adultos de meiaidade e idosos. Psicologia: teoria e pesquisa, Brasília, v. 19, n. 1, p. 47-57, jan./abr. 2003.

RIZZOLLI, Darlan; SURDI, Aguinaldo C. Percepção dos idosos sobre grupos de terceira idade. Revista Brasileira de Geriatria e Gerontologia, Rio de Janeiro, v. 13, n. 2, p. 225-234, ago. 2010.

SÁEZ CARRERAS, Juan (Org.). Educación y aprendizaje en las personas mayores. Madri: Dykinson, 2003.

SERVIÇO SOCIAL DO COMÉRCIO (SESC). O século da terceira idade. São Paulo: Sesc, 2003.

TODARO, Monica A. Vovô vai à escola: a velhice como tema transversal no ensino fundamental. Campinas: Papirus, 2009.

TRIBESS, Sheila; VIRTUOSO JUNIOR, Jair S.; PETROSKI, Édio L. Estado nutricional e percepção da imagem corporal de mulheres idosas residentes no nordeste do Brasil. Ciência \& Saúde Coletiva, Rio de Janeiro, v. 15, n. 1, p. $31-38,2010$.

ZITKOSKI, Jaime J. Paulo Freire e a educação. Belo Horizonte: Autêntica, 2010.

Recebido em 31/05/2012

Aprovado em 16/09/2012 